\title{
Inter-Comparison of Coastal Models: Case Study of Storm Surge at Nemuro in Japan
}

\author{
Ryota Nakamura, Toyohashi University of Technology, r-nakamura@ace.tut.ac.jp \\ Martin Mäll, Waseda University, mallmartin4@gmail.com \\ Tomoya Shibayama, Waseda University, shibayama@waseda.jp \\ Shigeru Kato, Toyohashi University of Technology, s-kato@ace.tut.ac.jp
}

\section{BACKGROUND}

The numerical coastal circulation models play an essential role in predicting storm surges. Several models (e.g. ADCIRC: Dietrich et al., 2004, FVCOM: Chen et al., 2003) have been previously inter-compared (Kerr et al., 2013; Chen et al., 2013). In these studies, storm surges were reproduced in locations where the bathymetry has a gradual increase from offshore to coast, within a closed gulf. On the other hand, there are few studies in regards to modelling storm surge where the near coast bathymetry is steep and connected to open ocean. Considering the storm surge dependence on local bathymetry, it can be important to conduct an intercomparison of ocean circulation models in such a region. In this study, numerical coastal circulation models (2DADCIRC and 3D-FVCOM) are compared by using a 2014 Dec. storm surge event at Nemuro city in Hokkaido (Japan), which was caused by a rapidly intensified extratropical cyclone approaching the area. In this region, local bathymetry is steep due to Japan Trench (Fig. 1). The cyclone caused a storm surge of nearly up to $1.8 \mathrm{~m}$ within the Nemuro city between 00:00 UTC $16^{\text {th }}$ and $17^{\text {th }}$ Dec. 2014. The aim of this study is to evaluate the performance of ocean circulation models using several air-sea drag coefficients and contribute to inter-comparison studies using $A D C I R C$ and FVCOM.

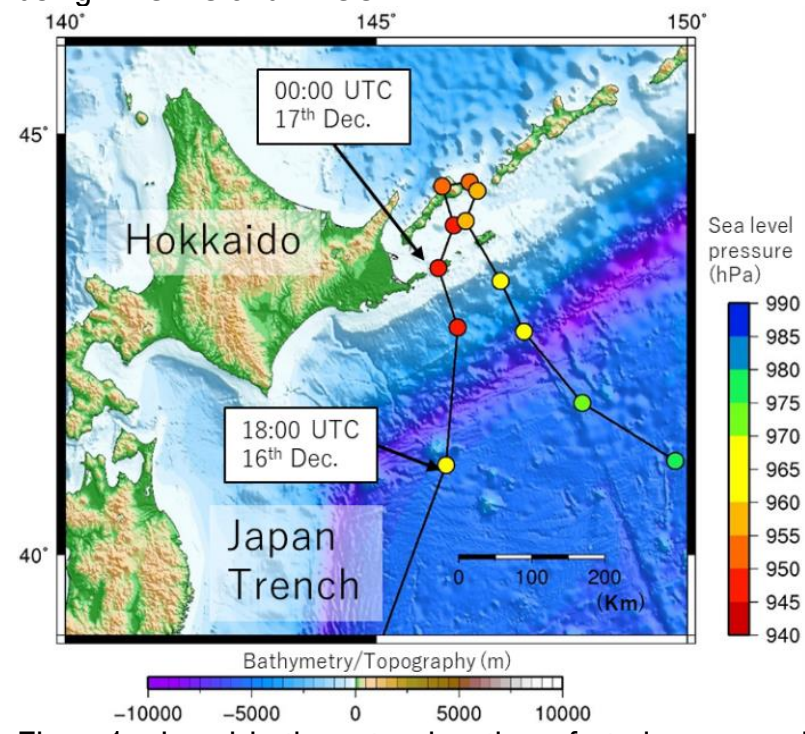

Figure1 - Local bathymetry, location of study area and sea level pressure of extra-tropical cyclone for every 3hour (extracted from GPV-MSM) in the middle of Dec. 2014

\section{INITIAL AND BOUNDARY CONDITIONS}

The initial and boundary conditions for both models are set as homogenously as possible. The ocean circulation simulations were conducted on the same unstructured grids and bathymetry (Fig. 2). The long fetch from Nemuro Bay to Western Pacific Ocean was required to accurately reproduce the sea elevation. The bathymetry for unstructured grids for both models was constructed from a combination of GEBCO, ocean depth data offered by Japan Coast Guard and from local charts of Nemuro port. The boundary condition at the open ocean was set for astronomical tide predicted by Nao.99b (Matsumoto, 2000 ). For forcing, the wind velocity and minimum seal level pressure from GPV-GSM and GPV-MSM (developed by Japan Meteorological Agency) were used. The variables of surface meteorological conditions on structured grids of GPV-GSM and MSM were linearly interpolated onto unstructured grids of the ocean models. The wind velocity was altered to wind stress employing commonly used three drag coefficients proposed by $\mathrm{Wu}$ (1982) with upper limitation of 0.003 , Honda (1980) with the constant coefficient over $30 \mathrm{~m} / \mathrm{s}$ and Large \& Pond (1981) with the constant coefficient over $25 \mathrm{~m} / \mathrm{s}$ (hereafter, Wu, Honda, Large case, respectively). The reason for using the three types of coefficients is to try to consider uncertainty of our understanding of momentum transfer on air-sea surface (e.g., Powell, 2006). In addition, it is better to be noted that there is a different treatment of surface variables between FVCOM and ADCIRC. The wind forcing variables are required on the unstructured nodes for ADCIRC, whereas for FVCOM they are required on the unstructured cells, which may cause slight differences in the sea level estimations.

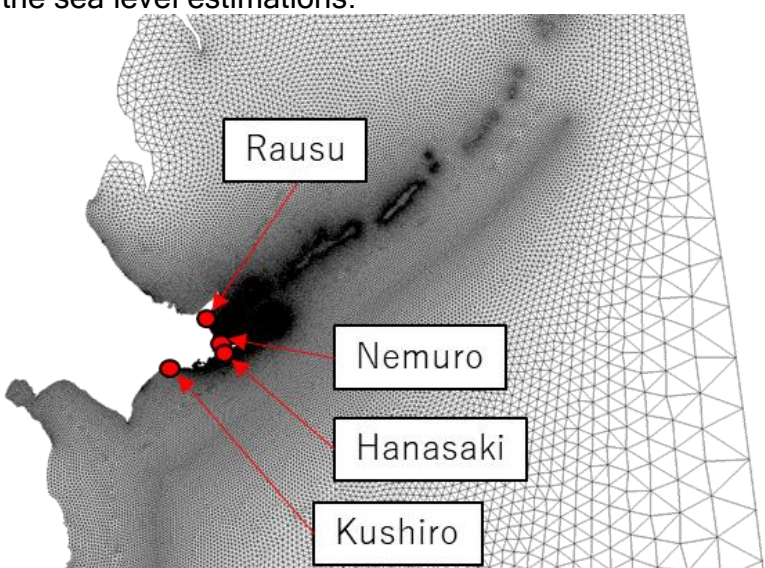

Figure 2 - A segment of unstructured grids for FVCOM and ADCIRC with the location of tide stations

\section{RESULTS}

Mean Square Root Error (MSRE) and coefficient of correlation $(R)$ between simulations and observations are used as an indicator to evaluate the performance of numerical modelling. The results for wind velocity and sea level pressure, predicted by GPV-MSM, are compiled in Table 1. It can be indicated that the surface meteorological variables, predicted by GPV-MSM, are highly consistent with observations at Nemuro station. The sea level validation period is from $10^{\text {th }}-19^{\text {th }} \mathrm{Dec}$. 2014 , over the span of 9 days. In the validation period, sea levels predicted by both models are in a good agreement with the observations at all tide stations (Table-1, Fig. 3), with $\mathrm{R}$ values over 0.85 and RMSE nearly up to $0.20 \mathrm{~m}$. Also the simulated sea level tendencies, for all the cases, are fairly similar (such as in 
Table1 - Comparison of wind velocity, sea level pressure (SLP) and sea level (S.L.) between simulation and observation in several stations

\begin{tabular}{|l|c|c|c|}
\hline \multicolumn{1}{|c|}{ Location } & RMSE & R & \\
\hline \hline Nemuro & & & \\
\hline Wind velocity & 2.22 & 0.92 & \\
\hline SLP & 0.89 & 1.00 & \\
\hline \multicolumn{1}{|c|}{ Location } & RMSE (ADC/FVM) & R (ADC/FVM) & Max (Obs.: ADC/FVM) \\
\hline \hline S.L.(Large) & & & \\
\hline Rausu & $0.19 / 0.18$ & $0.90 / 0.89$ & $\mathbf{0 . 9 4 :} 0.84 / 0.82$ \\
\hline Kushiro & $0.21 / 0.20$ & $0.89 / 0.88$ & $\mathbf{0 . 9 0 :} 0.77 / 0.79$ \\
\hline Nemuro & $0.20 / 0.20$ & $0.93 / 0.91$ & $\mathbf{1 . 7 7 :} 1.57 / 1.86$ \\
\hline Hanasaki & $0.24 / 0.23$ & $0.89 / 0.87$ & $\mathbf{1 . 0 4 :} 0.99 / 1.02$ \\
\hline S.L. (Wu) & & & \\
\hline Rausu & $0.19 / 0.18$ & $0.90 / 0.88$ & $\mathbf{0 . 9 4 :} 0.85 / 0.82$ \\
\hline Kushiro & $0.22 / 0.21$ & $0.89 / 0.88$ & $\mathbf{0 . 9 0 :} 0.77 / 0.79$ \\
\hline Nemuro & $0.20 / 0.21$ & $0.93 / 0.91$ & $\mathbf{1 . 7 7 : ~} 1.66 / 2.00$ \\
\hline Hanasaki & $0.24 / 0.24$ & $0.89 / 0.87$ & $\mathbf{1 . 0 4 : ~} 1.00 / 1.04$ \\
\hline S.L. (Honda) & & & \\
\hline Rausu & $0.19 / 0.18$ & $0.90 / 0.89$ & $\mathbf{0 . 9 4 :} 0.84 / 0.82$ \\
\hline Kushiro & $0.21 / 0.20$ & $0.89 / 0.88$ & $\mathbf{0 . 9 0 :} 0.77 / 0.79$ \\
\hline Nemuro & $0.20 / 0.20$ & $0.93 / 0.92$ & $\mathbf{1 . 7 7 :} 1.54 / 1.81$ \\
\hline Hanasaki & $0.24 / 0.23$ & $0.89 / 0.87$ & $\mathbf{1 . 0 4 :} 0.99 / 1.02$ \\
\hline & & & \\
\hline
\end{tabular}

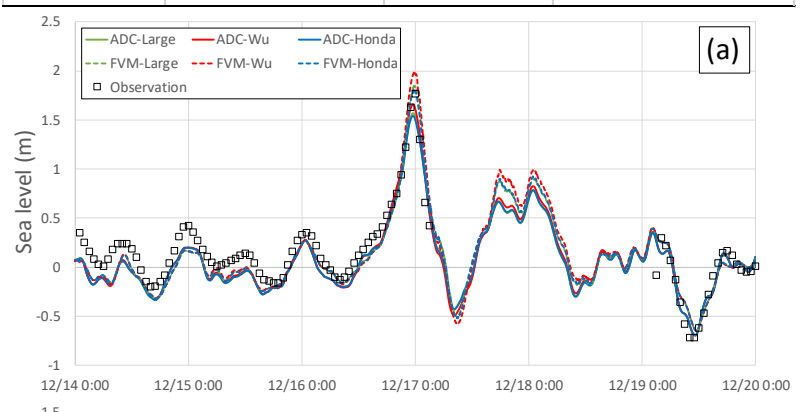

(b)

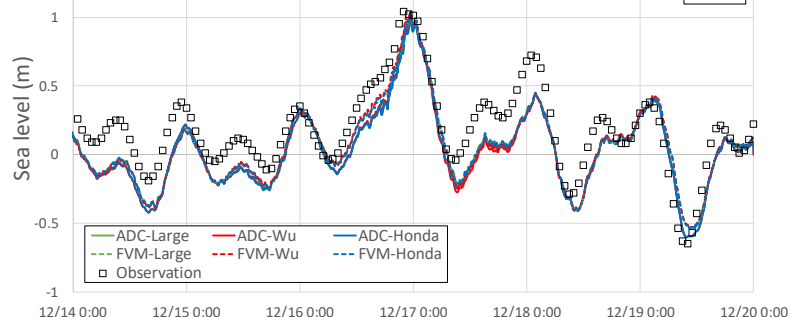

Figure 3 - The results of sea level on time series among the cases at Nemuro (a) and Hanasaki (b) tide station

Fig. 3). The exceptional case, however, is during the period of storm surge event at Nemuro tide station. In this period, it is shown that the maximum sea level is somehow deviating among all the cases (Table-1 and Fig. 3 ). While comparing the impact of each wind drag coefficient to sea surface elevation, the coefficient of Wu provides the maximum sea surface elevation among the cases, implying that this coefficient may have the potential to induce the largest momentum transfer on the air-sea surface. On the other hand, remarkable deviation of sea surface elevation could not be found between the Honda and Large case.

Although FVCOM simulates relatively larger maximum elevation of sea level than ADCIRC at Nemuro tide station (Fig. 3), it is difficult to find the sea level differences between the models at other stations. Based on these findings, it can be said that the overall performance in estimating sea levels is quite similar between the models. Also the differences of simulated sea levels at Nemuro

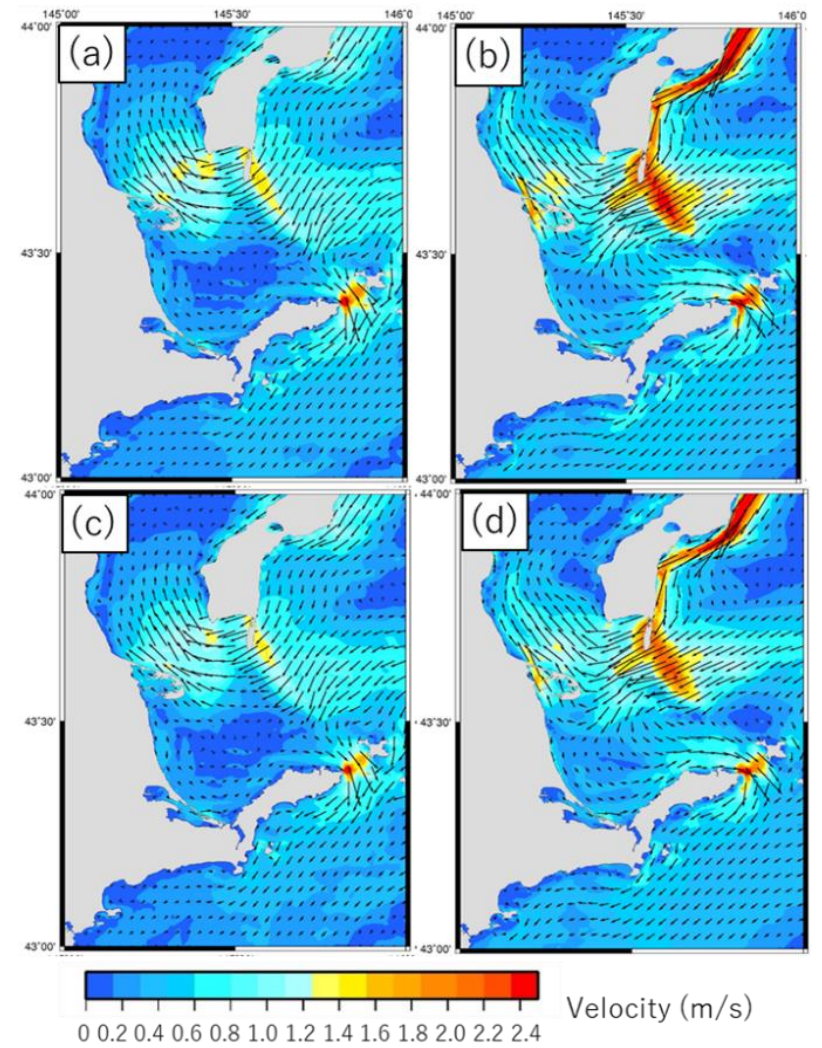

Figure 4 - The depth averaged current velocity in Nemuro Bay at 00:00 UTC 17th Dec. 2014. Four cases are shown: ADCIRC with Wu (a), FVCOM with Wu (b), ADCIRC with Honda (c) and FVCOM with Honda (d)

tide station can be attributed to the spatial variations of the simulated current velocities within Nemuro Bay (Fig. 4). FVCOM produces stronger current velocity fields than $A D C I R C$, which may cause the deviation in the estimation of the sea surface elevation.

\section{CONCLUSION}

In terms of sea level, the modelling performances are almost similar for both ADCIRC and FVCOM cases. On the other hand, in Nemuro Bay, FVCOM simulates larger current velocities than ADCIRC, which may lead to deviations of up to dozens of centimeters in the peak sea level, at Nemuro station. Also, it should be noted that due to the lack of the observation of current velocity, it cannot be concluded which of the models is better at estimating ocean circulations. Validation of current velocities between the models should be treated as future tasks.

\section{REFERENCES}

Chen et al. 2003: J. Atmos. Oceanic Tech, 20, 159-186. Chen et al., 2013: J. Geophys. Res. Oceans, 118, 1-20 Luettich., et al.: 2004, http://adcirc.org/adcirc_theory_200 4_12_08.pdf. Honda et al., 1980: J Coast Eng JSCE 27:90-93 (in Japanese). Kerr et al., 2013: JGR:Oceans, Vol.118, 5129-5172. Large et al., 1981: J. Phys. Oceanogr., 11, 324-336. Matsumoto et al., 2000: Journal of Oceanography, 56, 567-581, 2000. Powell et al., 2006: Nature, 422, 279-283. Wu, 1982: JGR: 87, C12, 9704-9706. 